\title{
Application on Task-based Language Teaching in Japanese Conversation Teaching
}

\author{
Jinling Qi \\ Department of Foreign Languages, Liaoning Institute of Science and Engineering, Jinzhou, 121013, \\ China
}

516607310@qq.com

Keywords: task-based language teaching; Japanese conversation teaching; application suggestions; task design principles

\begin{abstract}
Aiming at the problems that teaching material applicability is not strong, the lack of Japanese context, single teaching methods, students passively accept, knowledge as the center and the lack of evaluation mechanism and others exist in the Japanese conversation teaching, this paper makes research based on the task-based teaching method. The basic theory of task-based teaching methods is expounded, the principle of Japanese conversation teaching task design is analyzed, the application suggestions of task-based teaching methods in the Japanese conversation teaching are put forward. Specific recommendations are as follows: according to students' ability and teaching stage design different difficulty levels of Japanese dialogue teaching task, adopt the way that "listening promotes saying, reading promotes saying, writing promotes saying" way, adopt the Japanese conversation comprehensive evaluation system based on the combination of formative evaluation and summative evaluation, teachers change the teaching concepts and constantly improve their own level.
\end{abstract}

\section{Introduction}

Japanese conversation teaching is the important link of Japanese study, which is a professional basic course cultivates students convert learned Japanese comprehensive knowledge into practical language abilities and skills, and a practical course contains Japanese skills and abilities. Through learning this course, students can talk properly according to general scenes of daily life; make coherent speech according to general topics of social life; more accurately express their own thoughts and feelings, with accurate pronunciation, natural intonation, correct grammar, appropriate language applying. Language skills, language knowledge, cultural awareness and other elements are organically combined to promote each other, step by step, learned knowledge in the classroom are applied to the actual to ultimately achieve the purpose of communication. In addition, the text content of conversation lessons is rich and strong interesting, through learning understanding the knowledge of Japanese society, nature, culture, history and literature to help students broaden knowledge, strengthen the ability of comprehensive use of the Japanese language, all-round developments in listening, speaking, reading, writing and other aspects. Along with the deepening of economic and cultural exchange between China and Japan, the social demand for Japanese talents is increasing more and more, Japanese learners are also increasing. Social needs the compound and applied Japanese talents, which puts forward new requirements on the practical ability of Japanese, Japanese oral language teaching also should keeps pace with the times. The teaching method is the important means to realize teaching goals, which directly affects the teaching effect, therefore, it is necessary to change traditional teaching methods, fully mobilize students' enthusiasm. This paper makes researches based on the task-based teaching method to service for cultivating the ability of students' Japanese communication.

\section{Existing Problems in Japanese Conversation Teaching}

Current Japanese conversation teaching exists many problems, specific summaries are as follows:

First, the applicability of teaching materials is not strong. Teaching materials are the important 
tool for students to acquire system knowledge, develop intelligence and improve ideological consciousness. Teaching materials are not general materials or reading materials, which need to be specially developed and written according to the purpose of education and students' physical and mental development rules and cognition characteristics. Current Japanese conversation teaching materials, the practice form is single, some topics are more difficult and break away from the reality, not involve the cognitive context, which cannot improve the pragmatic competence. Many teachers in aspects of the teaching material selection ignore the convergence of conversation classes between intensive reading courses and listening classes, which causes that words and grammar interpretation takes more time than before.

Second, the lack of Japanese context. Context is the use environment of language, which is not only limited in pronunciation, vocabulary, grammar and other aspects, but also linked with the discourse, which includes subjective and objective factors. Among them, the subjective factor is the speaker's own factors, which includes identity, occupation, thought, accomplishment, character, situation, mood and other aspects. The objective factors include time, place, occasion, object and other aspects. Due to the limitation of Japanese conversation classroom teaching time and means, a real context cannot be constructed, the phenomenon often appears that students can understand all of words and grammar, but cannot express speakers' intention.

Third, the teaching method is single. Teaching method is the used teaching tools in the process of teaching, which includes modern teaching methods and traditional teaching methods, such as slides, tape recorders, blackboard, multimedia, physical display table and others. The quality of oral language teaching methods directly affects students' willingness and ability to express in Japanese. But in Japanese conversation teaching activities, teachers usually adopt the means that speak, blackboard-writing or interpretation of articles and others to teach the contents of teaching material to students, and assisted by mechanical conversation practice, this kind of inflexible teaching means cannot arouse students' interest.

Fourth, students' passive acceptance. Influenced by junior middle school and high school, the classroom teaching is a model which takes the injection and teachers as the center, explain as the main, students passively accept knowledge, which performed in the willingness to remember words and study grammar. But don't like to read and practice oral languages. In particular, introverted students dare not read aloud, speak aloud and practice aloud, it is difficult to break through spoken language difficulties. Also due to the lack of students' autonomous learning ability, knowledge and understanding of cultural background, it is difficult to carry out in-depth communication discussion.

Fifth, knowledge as the center. Current college Japanese teaching still takes "knowledge as the center", existing problems are: attach importance to cognitive process, ignore the feeling and experience process; attach importance to one-way transmission, ignore two-way communication; attach importance to knowledge infusion, ignore ability cultivation; attach importance to passive acceptance, ignore initiative innovation; attach importance to scientific knowledge, neglect humanities accomplishment; attach importance to common development, ignore personality shaping. Japanese conversation should focus on communication skills cultivation, but teachers outstanding knowledge imparting, don't achieve the purpose of conversation teaching.

Sixth, the lack of evaluation mechanism. Teaching evaluation is an activity which makes value judgments on teaching process and results according to teaching goals and service for teaching decision, the process which makes judgments on actual or potential value of teaching activities. Current Japanese grade exams and postgraduate entrance examination are both summative evaluation, affected by test conditions and environment, focus on "listening, reading, writing and translation" and others, spoken language is an important content of Japanese teaching, but not included in the scope of examination, so that it is not valued by teachers and students, ignoring the cultivation of spoken language ability.

\section{Basic Theory on Task-based Language Teaching}

Task-based Language Teaching refers to the teaching teachers carry out through guiding language learners to complete tasks in the classroom. A language teaching method which emphasizes 
"learning by doing", the development of communicative teaching methods, which has aroused wide attention in the world language education. The basic idea is that mastering language is mostly the result of using language in activities, rather than the result of simply training language skills and learning language knowledge. In teaching activities, teachers should focus on particular communication and language projects to design specific and operational tasks, students complete tasks through all sorts of language activity forms of expression, communication, negotiation, negotiation and inquiry, in order to achieve the purpose of learning and mastering language. Task-based teaching method process is shown in Fig.1.

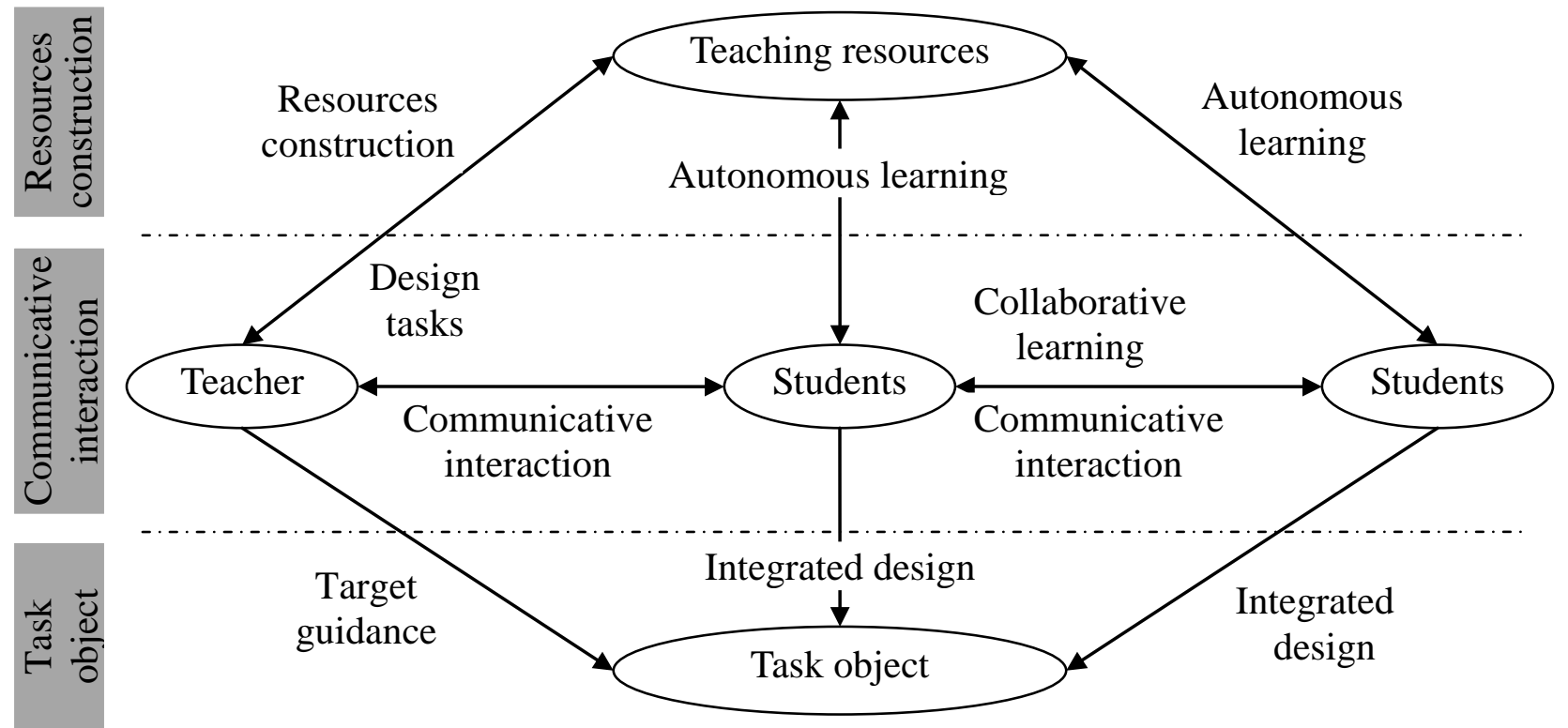

Fig. 1. Process on task-based language teaching

In the task-based teaching, teachers should design teaching activities from the perspective of students "learning", which makes students' learning activities have clear goals, and constitute a gradient of continuous activities. In various tasks designed by teachers, students can continuously acquire knowledge or draw conclusions to gain the ability of language applying, from the focus on language itself into the focus on language meaning. And with the continuous deepening of tasks, the whole language learning process will become more and more automated and independent. Task-based teaching method has the following advantages: completing a variety of task activities helps to stimulate students' learning interest; in the process of completing tasks, combining language knowledge and language skills help to cultivate students' comprehensive language using ability; promoting students to actively participate in language communication activities to inspire imagination and creative thinking, which is conductive to play the subjective role of students; there are a lot of group or double activities in the task-based teaching, everyone has their own tasks to complete, which can better carry on teaching for all students; the content covers a wide range, a large amount of information, which helps to broaden students' knowledge; learning knowledge in activities, cultivating the capacities of interpersonal communication, thinking, decision and strain, which is conducive to the all-round development of students; in task-based teaching activities, under teachers' inspire, each student has the opportunity to think independently, actively participate in, which is easy for students to maintain the enthusiasm of learning, develop good study habits.

\section{Principles of Task Design in Japanese Conversation Teaching}

The task-based teaching method emphasizes "communicative classroom teaching, mobilizative communication teaching, task-based activity teaching, actualized task teaching", the task design is the key to carry out teaching, which should follows the following principles:

First, dynamic principle. "Dynamic" refers to a constant changing and adjustable form. Japanese education factors are constantly changing, Japanese teachers should full grasp the dynamic connotation of education factors, especially learning purpose and motivation, the constant changing 
of learning interest and learning difficulties of learners, and according to dynamic Japanese spoken education factors, constantly adjust teaching tasks and design new teaching tasks, meanwhile, adjust to teaching materials, teaching process, teaching strategies, teaching methods and skills, education technology to improve the education quality, teaching efficiency and results of spoken Japanese.

Second, interactive principle. The ultimate goal of language learning is communication, the core of communication is the interaction. The interaction of language creates a large amount of opportunities of language output of information input for learners. Interactivity is especially suitable for spoken language teaching. Through interaction, students' creativity in the use of language to complete the task, and combining knowledge such as grammar, vocabulary and sentence patterns to develop language ability; in the process of interaction, simulating real communicative environment can integrate various language knowledge and expression methods which have been mastered; the interaction between students can provide more opportunities for input and output, and make up for the lack of classroom teaching.

Third, authenticity principle. "Reality" refers to the form conforms to the actual and non virtual. Japanese teachers should grasp the true connotation of educational factors, especially the real purpose of Japanese spoken education, learners' real purpose and motivation, real learning interest and learning difficulties, on the basis of the grasp of the real connotation of education factors, in the Japanese spoken language teaching design teaching tasks with real semantic, real context and real pragmatic. Pay attention to the real teaching contents, the real teaching process, the real teaching methods and the real education technology.

Forth, communicative principle. "Communicative" is the important concept of the Japanese conversation teaching. Communication process is not a simple sum of listening and speaking, but the interactive process between two sides which takes listening and speaking as the core. Task design should starts from the actual demand, highlights communication ideas, transfers information and communicates feelings, the main design of tasks' contents is as follows: express personal reaction, find and convey information, solve problems, telephone conversations, discuss ideas, language games, play social roles, and ask others to do things and so on. Compared with the traditional dialogue teaching, while the coordinated development of listening and speaking ability, pay attention to the exchange and communication between people.

Fifth, interest principle. Motivation and interest are the main motivation that students learn behavior. One of the advantages of task-based teaching methods is to stimulate students' learning motivation through interesting classroom communicative activities, so that they actively participate in the study. Therefore, the interest is an important link of the task design. Covering boring knowledge in interesting task activities to let students to carry on practical operations. The interest of Japanese conversation except comes from the task itself, but also from many aspects, such as multi person participation, multi directional interaction, the interpersonal communication and emotional communication in task performance, the excitement and a sense of achievement after solving problems or completing tasks and so on.

\section{Application Suggestions on Task-based Language Teaching in Japanese Conversation Teaching}

Aiming at the existing problems in Japanese conversation teaching, following the principles of Japanese conversation teaching task design, combining with author's years of Japanese conversation teaching experience, application suggestions of proposed task-based teaching methods in Japanese conversation teaching are as follows:

First, according to the ability of students and teaching stages design different difficulty levels of Japanese conversation teaching tasks. Specific can contain three levels: primary tasks, namely simple communicative tasks, which are suitable for students with the lower ability and the early stage of teaching, conversation contents are restricted in the daily life, learning, and simple social communication range, language functions give priority to the understanding, inquiry and social interaction, common used words or simple discourse structure, specific contents, there are obvious signal words or logical ways; intermediate tasks, namely general communicative tasks, which are 
suitable for students with the secondary ability and the intermediate stage of teaching, involved communicative activities are in the range of daily life, study, work, social and profession, language functions give priority to explain, description and evaluation, the discourse has a certain connection program, the content is relatively complete, which needs for a paragraph to understand and express; advanced tasks, namely complex communicative tasks, which are suitable for students with the high ability and the late stage of teaching, involved communicative activities are in the range of high level of learning, work, sociality, social culture and business, language functions give priority to the conversation, discussion and emotion expression, strong sexual characteristics discourse parataxis, free connection program, the content is abstract, which needs a large section of a chapter to understand and express, and it is necessary to understand the relevant cultural meanings.

Second, the use of "listening promotes speaking, writing promotes speaking, writing promotes speaking" approach. Cannot simply carry on conversation teaching, but combine "listening, reading and writing" together. Listening is the basis of speaking, through listening practice, dialogue scenes actually appear, it is easier for students to grasp and comprehend Japanese conversation presentation skills. At the same time, through listening practice, students can consciously recognize the voice and intonation problems exist in the Japanese conversation, so as to adopt remedy and corrective measures to avoid incorrect enunciation and pronunciation. Teachers should also encourage students to follow the tape to imitate, change dialect Japanese; reading is also the basis of speaking, develop the habit of reading. The process of reading is also the process of observation and simulation, it does not deliberately to study grammar, but read aloud again and again, paying attention to the use of simulation, reading to a certain extent will naturally remembers what they read, and speak out in the form of conversation; at the same time, reading subject should has a wide range, rich contents, a large amount of information, a lot of knowledge, and ensures sufficient language knowledge input; systematic copying and writing, and gradually improve the requirements of writing speed, at the same time with the exercises that making a sentence, composition, dictation and conversation, students will naturally develop the good habit that using accurate words, making sentences accordance with rules, clear composition structure. And through the appropriate conversation practice, which makes students' conversation ability improved and perfected.

Third, the use of Japanese conversation comprehensive evaluation system which combined formative evaluation and summative evaluation. Formative evaluation is the evaluation made for students' developments of performance, obtained achievements and reflected emotion, attitude, strategies and other aspects in the process of daily learning, which is the developmental evaluation made on the basis of the continuous observation, record and reflection of the learning process. Formative evaluation makes evaluation on the students' usual conversation performance and conversation learning ability, the purpose is to encourage students to attach great importance to usual learning, help students to control the learning process, which makes students obtain a sense of achievement, enhance self-confidence, cultivate the spirit of cooperation. Students change from passive recipients into active participants, emphasize on open and loose evaluation atmosphere, promote the diversification of evaluation methods, improve students' personal development and Japanese teaching quality; summative evaluation is the evaluation made for judging effect after teaching activities, which is an important way to test students' comprehensive use of language ability development degree, also one of important indicators reflects the teaching effect and quality. The summative evaluation of Japanese conversation teaching should do: test questions are conformed to communicative behavior, which cover students' language knowledge points, the difficulty is appropriate, effectively test the flexibility of students' conversational expression.

Forth, teachers change teaching concepts and constantly improve their own levels. Task-based teaching fully reflects the teaching concept which takes students as the center and takes students' developments as the fundamental, requires teachers based on students themselves to focus on the sustainable development of students in the Japanese conversation teaching process. Therefore, teachers must change concepts, update teaching methods, constantly improve their own cultural quality, language ability, teaching skills and teaching theory. In the teaching process, according to the needs that students construct language systems and language applications, selecting interesting 
and practical topics to design specific learning tasks; according to the teaching environment, classifying different tasks to combine into the natural task cycle; in the classroom using Japanese fluently to communicate with students naturally; with the enhancement of students' learning autonomy, teachers must change from "lecturer" to "communicator"; the uncertainty of task-based classroom communication requires teachers to have better classroom management and random strain capacity to effectively control the ways and rules that students complete tasks.

\section{References}

[1] Z. M. Qin, "On the Relationship Between the Use of Japanese and Its Context," Modern Management, vol. 60, no. 1, pp. 116-118, 2010.

[2] C. M. Wang, "On the context of foreign language learning," Foreign language teaching and research, vol. 39, no. 3, pp. 190-197, 2007.

[3] L. L. Hou, "Study on oral teaching means for Japanese primary," Teaching of Forestry Region, vol. 26, no. 4, pp. 60-61, 2010.

[4] H. J. Yan, "Problems and Countermeasures in oral English Classroom Teaching," Modern Management, vol. 6, no. 9, pp. 164-165, 2009.

[5] D. M. Sun, "On the Assessment Mechanism of Oral English Teaching," Journal of Weifang Educational College, vol. 24, no. 6, pp. 103-104, 2011.

[6] J. P. Wang, "The design principles and implementation strategies of task based teaching in College English," Journal of Wuhan Metallurgical Manager's Institute, vol. 20, no. 3, pp. 42-64, 2010.

[7] J. Ding, "An Empirical Study of Task-based Approach of Oral Business English Teaching at Higher Vocational College," Master's degree of Suzhou University, 2015.

[8] M. Wang, "Teaching Design in Primary Stage of Oral TCSL Based on Task-Based Approach," Master's degree of Northeast Normal University, 2012.

[9] Y. Nie, "Exploration and practice of task-based spoken Chinese teaching of teaching Chinese as foreign language," Master's degree of Zhejiang University, 2012.

[10] C. Liao, L. N. Ru, "Phased application in Japanese spoken language teaching for communicative approach," Journal of the Socialism Institute of Yunnan, vol. 15, no. 5, pp. 227-228, 2013. 